\title{
Investigações psicológicas no ciberespaço: Desenvolvendo modelos preditivos sobre a adesão às crenças ufológicas
}

\author{
Marcos Emanoel Pereira \\ Universidade Federal da Bahia
}

\begin{abstract}
RESUMO
O objetivo do presente artigo procura é desenvolver, mediante o uso da regressão linear, modelos estatísticos capazes de isolar e avaliar o impacto de uma série de variáveis independentes - interesse pelo assunto, filiação a grupos ufológicos e grau de conhecimento - sobre o grau de adesão às crenças ufológicas e, em seguida, partir da modelagem de equação estrutural, elaborar modelos explicativos capazes de se ajustar aos dados obtidos em uma pesquisa empírica sobre as crenças ufológicas e os extraterrestres. Os resultados obtidos pela regressão linear indicaram que os modelos elaborados possuem um poder preditivo relativamente alto e uma qualidade bastante aceitável, a se considerar os índices de ajustamento da equação estrutural, que apresentaram valores bastante toleráveis para estudos conduzidos nos domínios das ciências comportamentais. Finalmente, foram apresentadas algumas implicações destes modelos para a pesquisa psicossocial sobre as crenças, em especial sobre as crenças ufológicas.
\end{abstract}

Palavras-chave: crenças; crenças compartilhadas; ufologia.

\section{ABSTRACT \\ Psychological research in cyberspace: \\ Developing predictive models about endorsement of ufological beliefs}

This paper aimed to develop, through the use of linear regression techniques, statistical models capable of isolating and evaluating the impact of some independent variables - interest in the topic, affiliation to ufological groups, and degree of knowledge - on the adherence to beliefs about ufology and extraterrestrial entities and then, using structural equation modeling, develop explanatory models that fit data obtained in empirical research about UFO and extraterrestrial beliefs. The results of linear regression suggests that the models have a high predictive power and structural equation modeling suggests a good fit of models, presenting results compatible with the standards of behavioral sciences. Finally, the implications of these models to the psicossocial research on beliefs, specially the ufological beliefs, are discussed.

Keywords: beliefs; shared beliefs; ufology.

Em trabalho anterior, partindo da suposição de que o conhecer e o crer se encontram inextricavelmente interligados, esperava-se encontrar evidências que apontassem para um forte relacionamento entre o grau de conhecimento sobre o assunto e o grau de adesão às crenças ufológicas. As evidências obtidas, no entanto, apontaram que o impacto do conhecimento na adesão às crenças ufológicas não é intenso e sugeriram, em contrapartida, que a adesão a este sistema de crenças é moderada, sobretudo, por um fator motivacional, o grau de interesse pelo assunto, e por um fator psicossocial, o grau de filiação com grupos de investigação ufológicos (Pereira, Silva \& Silva, 2006).
Dentre as cinco crenças consideradas no artigo anterior, serão aqui analisadas, com mais detalhes, duas delas, a crença de que a humanidade sofre a influência dos extraterrestres e a difundida crença acerca das teorias conspiratórias. Conforme especificado no estudo aludido, a crença sobre os extraterrestres e a humanidade inclui questões como a origem extraterrestre da civilização humana, a visita de objetos voadores não identificados ao Planeta Terra, o crescimento constante de aparições de objetos voadores não identificados nas últimas décadas, assim como a hipótese dos objetos voadores não identificados serem oriundos de civilizações tecnologicamente mais avançadas que a nossa. A crença sobre os extraterrestres e 
as teorias conspiratórias é constituída por indagações a respeito da possibilidade de alguns dos artefatos criados pelos homens terem sido construídos com base na tecnologia obtida a partir de destroços de veículos extraterrestres, de que o sigilo em torno das informações sobre os objetos voadores não identificados decorre da necessidade de evitar pânico na população, de que os filmes de ficção científica podem ser considerados formas de preparar a opinião pública para a vindoura divulgação oficial sobre a existência de objetos voadores não identificados, de que autoridades civis e militares têm conhecimento da presença dos objetos voadores não identificados e de que, em última instância, está em curso uma conspiração para impedir que a população do nosso planeta conheça a verdade sobre os objetos voadores não identificados, desde que se aceite a existência de um acordo celebrado entre extraterrestres e alguns grupos humanos.

O presente artigo é presidido por um duplo objetivo; por um lado, procura-se desenvolver, mediante o uso da regressão linear, modelos estatísticos capazes de isolar e avaliar o impacto de uma série de variáveis independentes sobre o grau de adesão a cada uma das crenças acima referidas e, em seguida, com base no uso de procedimentos de modelagem de equação estrutural, tenta-se desenvolver modelos explicativos capazes de se ajustar aos dados obtidos na pesquisa empírica realizadas nos anos de 2004 e 2005.

Acredita-se que os resultados aqui apresentados se revestem de enorme importância na pesquisa em psicologia social, especialmente no que concerne ao tópico das crenças, um dos temas mais significativos da pesquisa psicossocial contemporânea. Qual a importância de se estudar estes tipos de crenças? A aceitação dessas crenças implicaria uma mudança substancial do entendimento acerca da posição ocupada pelos seres humanos no universo. Uma vez que a literatura psicanalítica alude às três grandes feridas narcísicas sofridas pela humanidade, a primeira imposta por Nicolau Copérnico, ao sustentar que o planeta Terra não ocupa uma posição privilegiada no universo, a segunda, sugerida por Charles Darwin, ao sustentar que o homem descende dos macacos e não se diferencia em sua natureza dos demais animais que evoluíram no nosso planeta e a terceira, imposta por Sigmund Freud, ao postular que a nossa vida consciente reflete apenas uma parcela da nossa vida mental, a adesão a esta crença implicaria um quarto grande golpe no orgulho humano, pois, uma vez aceita esta tese, segue-se que não podemos ser vistos como os únicos seres inteligentes no universo e, em uma formulação mais audaciosa, pode-se presumir que a humanidade pode ser considerada um grande campo de experiência para exercícios científicos conduzidos por inteligências superiores, capazes de exercer um insuspeito domínio sobre a humanidade.

As teses expostas por Bem (1973) e Rokeach (1981) sugerem que as reflexões sobre a natureza humana devem ser absolutamente centrais no nosso sistema de crenças. Conforme assinalado no artigo anterior, no domínio da pesquisa psicossocial sobre as crenças, o endossamento subjetivo é mais importante que o estatuto epistemológico (Oakhill \& Garnham, 1993), pois sejam ou não justificadas, a adesão ou o endosso de um sistema de crenças gera repercussões em vários planos, especialmente nas circunstâncias em que a crença é compartilhada por um número significativo de pessoas (Krüger, 1995; Pereira, 2002), como parece ser o caso atual das crenças ufológicas.

No livro Open and Closed Mind, Rokeach estabelece uma distinção entre pessoas de mente fechada e aquelas de mente aberta. Indivíduos de mente fechada se caracterizariam pela rejeição aberta de crenças que se opõem àquelas as quais aderem, por estabelecerem uma distinção rígida entre o que se pode acreditar e o que deve ser objeto de descrença, tenderiam a agrupar uma ampla variedade de crenças às quais não atribuem valor em uma única e mesma categoria, desenvolveriam uma relação de ansiedade uma vez que os se fundamentos das suas crenças fossem colocados em discussão, confiariam demasiadamente em argumentos fundados no princípio da autoridade e aceitariam sem reservas a crença de que o mundo é um lugar hostil e pouco hospitaleiro. Em contrapartida, aqueles de mente aberta evitariam rejeitar abertamente as crenças às quais não aderem, rejeitariam uma distinção rígida entre aquilo em que acreditam e aquilo em que não crêem, tenderiam a analisar de forma diferenciada as várias crenças as quais não aderem, evitariam organizar o pensamento com base em argumentos emanados de figuras de autoridade e tenderiam a ver o mundo como um lugar amigável e interessante para se viver (Rokeach, 1960).

Depreende-se da distinção estabelecida por Rokeach que aquelas pessoas que aderem às crenças ufológicas devem se considerar como indivíduos de mente aberta e que os seus críticos e detratores, especialmente os céticos, são julgados como rígidos e incapazes de avaliar o enorme conjunto de evidências obtidas pelos pesquisadores da ufologia e publicadas na literatura ufológica. Em contrapartida, os céticos e os descrentes nas hipóteses ufológicas tenderiam a considerar os 
ufólogos crédulos e pouco críticos em relação às pretensas evidências apresentadas nas pesquisas ufológicas.

\section{Modelos preditivos: elaboração e avaliação}

Adotando como ponto de partida os resultados previamente obtidos, observou-se um padrão diferencial de adesão às crenças, no sentido em que os participantes com um maior grau de conhecimento, com maior interesse e vinculados aos grupos de pesquisa tenderam a aderir mais intensamente às crenças ufológicas que os demais participantes. Com base nestes resultados, foram desenvolvidos uma série de modelos preditivos sobre as relações entre as variáveis psicossociais e demográficas e as crenças.

Os resultados da análise da crença sobre os extraterrestres e a humanidade encontram-se apresentados na Tabela 1. Nesse caso, foram incluídas as seguintes variáveis preditoras:

a) interesse pelo assunto, mensurada em um escala de 5 pontos;

b) as variáveis dummy filiado a grupo de pesquisa e pretende se filiar a grupo de pesquisa ufológico, definidas a partir da variável filiação a grupos de pesquisa ufológicas;

c) conhecimento, mensurada em uma escala de 7 pontos, obtido mediante um índice relacionado com o grau de conhecimento sobre eventos ufológicos;

d) as variáveis dummy católico e espírita, obtidas a partir da variável categórica religião; e

e) a variável idade.

TABELA 1:

Sumário da Regressão Linear para o Efeito das Variáveis Psicossociais e Demográficas Sobre a Adesão à Crença a Respeito dos Extraterrestres e a Humanidade

\begin{tabular}{lccc}
\hline \multicolumn{1}{c}{ Variável } & $\underline{\mathrm{B}}$ & $\underline{\mathrm{SEB}}$ & $\underline{\beta}$ \\
\hline Filiado a grupos ufológicos & -.42 & .09 & $-.17^{* *}$ \\
Pretende se filiar a grupos ufológicos & .17 & .07 & $.03^{*}$ \\
Conhecimento & .02 & .03 & .03 \\
Interesse pelo assunto & .63 & .04 & $.70^{* *}$ \\
Católico & .16 & .06 & $.09^{*}$ \\
Espírita & .23 & .08 & $.10^{*}$ \\
\hline Idade & .00 & .10 & $.13^{* *}$ \\
\hline
\end{tabular}

Nota. $R^{2}=.572(\underline{p}<.001) \quad{ }^{*} \underline{p}<.05 \quad{ }^{* *} \underline{p}<.001$

Mediante a análise dos betas padronizados verificou-se que a variável interesse pelo assunto possui o maior preditivo entre as variáveis entre as incluídas na equação de regressão, seguida pela variável filiado a algum grupo de pesquisa. Esta se caracteriza por apresentar um beta padronizado negativo, o que indica que se a pessoa for filiada a algum grupo de pesquisa, o seu nível de adesão à crença tende a decrescer. As demais variáveis exercem sempre o efeito aditivo e contribuem cada vez menos para a explicação do nível de adesão à crença.

A partir dos dados obtidos na Tabela 1 e da constante da equação de regressão, foi possível identificar a equação preditora do grau de adesão às crenças a respeito dos extraterrestres e da humanidade $(\mathrm{R}=$ $.762 ; r^{2}$ ajustado $\left.{ }^{=} .574\right)$, equação esta que pode ser expressa segundo a fórmula

$$
\begin{gathered}
I A C_{1}=1.322+(\text { Int } x .632)+(\text { Fil } x-.421+\text { Pret } x .173)+ \\
(\text { Ida } x .009417)+(\operatorname{Esp} x .233+\text { Cat } x .160)
\end{gathered}
$$

na qual o termo $I A C_{1}$ se refere à intensidade de adesão à crença 1 , o valor 1.322 corresponde a constante da equação de regressão, Int ao interesse pelo assunto, Fil ao fato da pessoa estar filiada a algum grupo de pesquisa ufológica, Pret, a indicação de que pretende se filiar a algum grupo de pesquisa, Ida à idade do participantes, Esp a adesão à religião espírita e Cat a adesão ao catolicismo.

Esta equação identifica, portanto, duas variáveis psicossociais, interesse pelo assunto e filiado/pretende se filiar a grupos de pesquisas ufológicas, e duas variáveis demográficas, a idade e a religião, como os principais preditores do grau de intensidade de adesão à crença sobre os extraterrestres e a humanidade. É importante assinalar, no presente caso, a ausência de influência da variável grau de conhecimento, que pouco contribui para a explicação da adesão à crença objeto de análise.

A partir desta equação é possível predizer os resultados das respostas de cada um dos participantes, 
de acordo com o raciocínio apresentado nos exemplos a seguir: se o participante não possui qualquer interesse pela pesquisa ufológica, não pretende se filiar a grupos de pesquisa ufológica, tem 35 anos de idade e é filiado à religião católica, espera-se que adesão à crença 1 seja de 2,25, em uma escala de 1 a 5 pontos; se, no entanto, o participante se mostrar muito interessado pela pesquisa ufológica, for filiado a um grupo de pesquisa, tiver os mesmos 35 anos de idade e aderir à religião católica, a equação de regressão indica que o grau de adesão à crença será de 3,74 ; no caso do participante com os atributos semelhantes ao anterior, mas que pretende se filiar a um grupo de pesquisa ufológica e professa a religião espírita, o resultado predito será de 4,61.

Para testar o poder preditivo desta equação de regressão, conduzimos uma análise com os dados relati- vos aos 129 questionários respondidos no ano de 2005, não utilizados para o desenvolvimento do modelo. Para tal, foram considerados como critério para a decisão quanto à precisão do poder preditivo da equação a comparação entre o resultado obtido e os resultados previstos, no sentido em que se o valor obtido tivesse incluído no intervalo de confiança de 95\% da regressão linear, o resultado seria contabilizado como previsto pelo modelo. Os resultados destas análises sustentam o ponto de vista de que a equação conseguiu prever $82,9 \%$ dos casos, com um erro médio de 0,17 unidades, em uma escala de 5 pontos. A distribuição dos erros pode ser observada no gráfico apresentado na Figura 1, onde se nota que afora alguns valores extremos, a ampla maioria dos casos distribuise em torno do valor zero, que corresponderia a uma previsão perfeita do modelo.

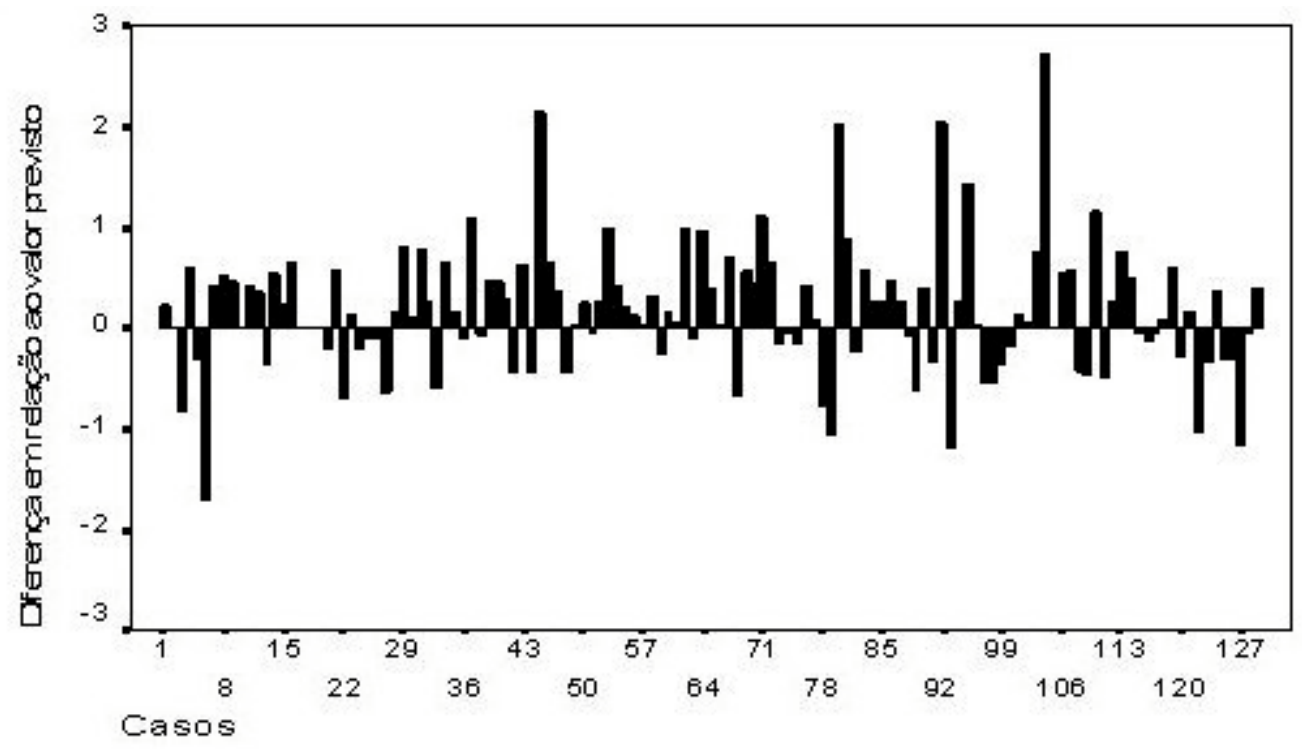

Figura 1. Gráfico relativo às diferenças entre os valores previstos e os valores obtidos pelos participantes em relaçăo à crença sobre os extraterrestres e a humanidade.

No que concerne a adesão à crença 5 , sobre os extraterrestres e as teorias conspiratórias, os resultados encontram-se apresentados na Tabela 2.

TABELA 2

Sumário da Regressão Linear para o Efeito das Variáveis Psicossociais e Demográficas sobre a Adesão à Crença sobre as Hipóteses Conspiratórias 


\begin{tabular}{lccc}
\hline \multicolumn{1}{c}{ Variável } & $\underline{\mathrm{B}}$ & $\underline{\mathrm{SEB}}$ & $\underline{\beta}$ \\
\hline Filiado a grupos ufológicos & -.79 & .10 & $-.28^{* *}$ \\
Pretende se filiar a grupos ufológicos & .26 & .07 & $.14^{* *}$ \\
Conhecimento & .11 & .04 & $.11^{*}$ \\
\hline Interesse pelo assunto & .58 & .04 & $.62^{* *}$ \\
\hline Nota. $R^{2}=.490(p<.001){ }^{*} \underline{p}<.05$ & ${ }^{* *} p<.001$ & &
\end{tabular}

Conforme se observa pelo valor do $\mathrm{r}^{2}$, o poder preditivo global desta equação de regressão é um pouco menor do que no caso da crença sobre os extraterrestres e a humanidade. Ainda assim, os resultados não podem ser considerados desprezíveis. Mediante a análise dos betas padronizados identificamos que 0 interesse pelo assunto continua a apresentar um maior impacto preditivo, seguido pela variável filiado a algum grupo de pesquisa, que uma vez mais sugere a tendência ao decréscimo no grau de adesão à crença quando o participante se filia a um grupo de pesquisa ufológica.

A partir dos dados obtidos na Tabela 2 e da constante da equação de regressão, foi possível identificar a equação preditora do grau de adesão às crenças a respeito das teorias conspiratórias, que pode ser formulada nos seguintes termos:

$$
\begin{array}{r}
I A C_{5}=1.330+(\text { Int } x .596)+(\text { Fil } x-.766+\text { Pret } x .259)+ \\
(\text { Con_al } x .225)
\end{array}
$$

Esta equação, ao contrário da anterior, sugere que nenhuma variável sócio-demográfica contribui para o modelo preditivo. Além disso, ratifica a importância das variáveis psicossociais interesse pelo assunto e filiado/pretende se filiar a grupos de pesquisas ufológicas. Nesse caso, pode-se constar, ao contrário do modelo anterior, que o grau de conhecimento sobre temas ufológicos contribui, embora modestamente, para o resultado final.

Uma vez mais, procurou-se testar o poder preditivo desta equação de regressão, adotando o procedimento discutido anteriormente. Os resultados destas análises sustentam o ponto de vista de que a equação conseguiu prever cerca de $80,6 \%$ dos casos, com um erro médio de 0,05 unidades, em uma escala de 5 pontos. A distribuição dos erros pode ser observada no gráfico apresentado na Figura 2.

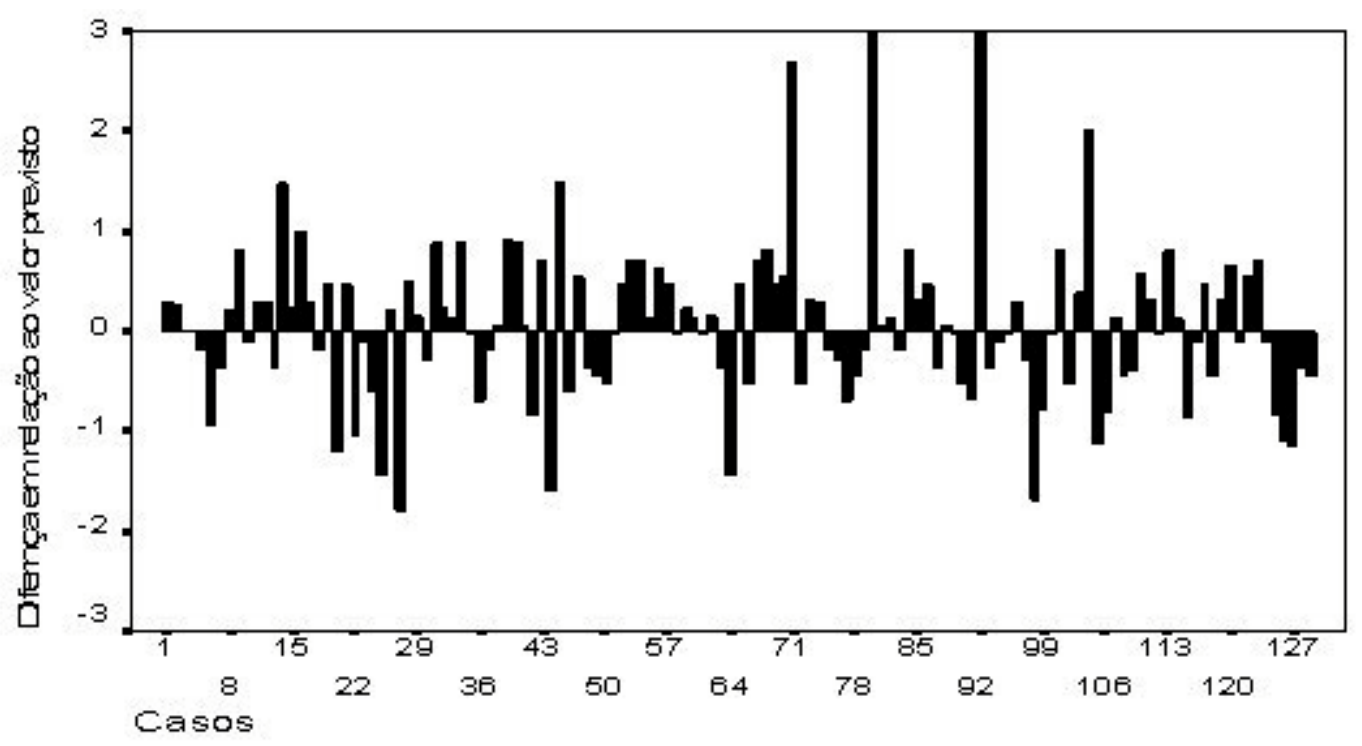

Figura 2. Gráfico relativo às diferenças entre os valores previstos e os valores obtidos pelos participantes em relaçăo à crença sobre os extraterrestres e as teorias conspiratórias.

\section{Redefinindo o modelo a partir do uso da equação estrutural}

Para avaliar de forma mais precisa o impacto das variáveis previamente identificadas sobre as crenças foi realizado um procedimento de modelagem dos 
dados, mediante o uso do software AMOS, especializado em equação estrutural (Byrne, 2001). Em decorrência da aplicação do princípio da parcimônia, e uma vez que a inclusão das variáveis sócio-demográficas pouco contribuiu para o resultado global, estas variáveis foram excluídas do modelo, cuja composição inclui apenas as variáveis interesse pelo assunto, filiação a grupos de pesquisa ufológicas e grau de conhecimento sobre o assunto.

O impacto de cada uma das variáveis sobre a crença a respeito dos extraterrestres e da humanidade pode ser depreendido mediante a análise da Tabela 3, na qual são apresentados os resultados de três modelos. O modelo I desconsidera o efeito da variável grau de conhecimento, levando em conta apenas o impacto das variáveis interesse pelo assunto e filiação a grupos de pesquisa ufológicas. O modelo II inclui a variável anteriormente referida, embora teste exclusivamente o efeito da variável grau de conhecimento sobre as variáveis interesse pelo assunto e filiação a grupos ufológicos, sem levar em consideração o impacto direto sobre a crença. O modelo III, por sua vez, é o mais inclusivo, pois além de incluir as variáveis interesse pelo assunto e filiado a grupos ufológicos, leva em consideração tanto o impacto direto do grau de conhecimento sobre a crença, como também o impacto do grau de conhecimento sobre as variáveis interesse pelo assunto e filiado a grupos ufológicos.

TABELA 3

Modelos de Equação Estrutural para o Efeito das Variáveis Psicossociais sobre a Adesão à Crença a Respeito dos Extraterrestres e a Humanidade

\begin{tabular}{ccccccc}
\hline Modelo & GI & $\boldsymbol{x}^{2}$ & AGFI & CFI & ECVI & RMSEA \\
\hline I & 5 & 5,907 & .99 & .99 & .07 & .019 \\
II & 9 & $18,003^{*}$ & .97 & .99 & .11 & .044 \\
III & 8 & 14,762 & .97 & .99 & .11 & .041 \\
\hline
\end{tabular}

Nota. AGFI = adjusted goodness-of-fit-index; $\mathrm{CFI}=$ comparative fit index; ECVI $=$ expected cross-validation index; RMSEA = rootmean-square error of approximation.

${ }^{*} \underline{p}<.005$

O exame dos indicadores de ajustamento do modelo (RMSEA, GFI, CFI) sugerem que os três modelos são aceitáveis e apontam para uma leve tendência no sentido de favorecer a aceitação do modelo I, enquanto o exame do valor de $x^{2}$ sugere o descarte do modelo II, uma vez que apenas neste caso os valores foram estatisticamente significativos.

Acreditamos que a decisão quanto ao modelo a ser adotado deve estar subordinada a razões estatísticas e a razões teóricas. Segundo ponto de vista estatístico, o modelo I leva alguma vantagem sobre o modelo III, especialmente no que concerne ao indicador RMSEA. O problema com este modelo é que ele exclui a variável grau de conhecimento, que no nosso entendimento deve ser levada em consideração na elaboração de uma teoria geral das crenças. O modelo III, embora estatisticamente menos ajustado, atende melhor aos nossos requisitos teóricos, pois ele leva em consideração o grau de conhecimento. Tal como se observa no diagrama observado na Figura 3, se o impacto direto do grau de conhecimento sobre a crença não é digno de nota (coeficiente padronizado $=.08$ )., pode-se dizer que esta variável exerce um impacto considerável sobre o interesse pelo assunto, ao mesmo tempo em que influencia de forma clara a decisão do participante em se filiar aos grupos de pesquisas ufológicas (coeficientes padronizados $=.56$ e .35 , no caso das variáveis interesse e filiado, respectivamente). 


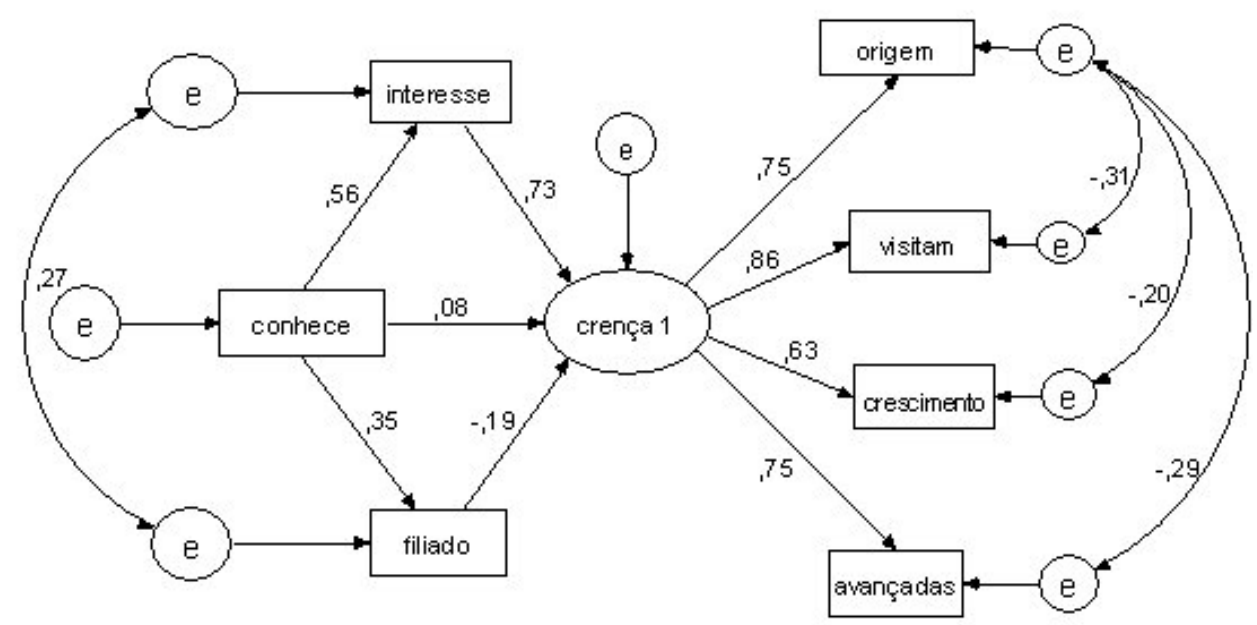

Figura 3. Diagrama da equaçẫo estrutural relativa ao efeito das variáveis psicossociais sobre a adesẫo à crença a respeito dos extraterrestres e a humanidade

Uma variável de natureza motivacional, o interesse pelo assunto, parece exercer um impacto mais intenso sobre a adesão a esta crença do que qualquer outra variável incluída no modelo (coeficiente padronizado $=.73$ ). Como se trata de um valor positivo, pode-se depreender que quanto mais alto o interesse pelo assunto, maior tende a ser a adesão à crença. Em contrapartida, a variável eminentemente psicossocial incluída na equação, a filiação a um grupo de pesquisa ufológica, correlaciona-se negativamente com a crença sobre os extraterrestres e a humanidade, o que permite concluir que adesão a esta crença tende a sofrer uma certa redução nas circunstâncias em que os parti- cipantes se filiam aos grupos de pesquisa ufológicos (coeficiente padronizado $=-.19$ ) .

Adotando um raciocínio semelhante, é possível considerar os modelos relativos às crenças a respeito dos extraterrestres e das teorias conspiratórias. Conforme se observa na Tabela 4, o modelo II deve ser descartado por razões estatísticas, enquanto os modelos I e III apresentam índices de ajustamento equivalentes. Por motivos já aludidos quando da análise do item anterior, uma vez mais a preferência recai sobre o modelo III.

TABELA 4

Modelos de Equação Estrutural para o Efeito das Variáveis Psicossociais sobre a Adesão à Crença a Respeito dos Extraterrestres e as Teorias Conspiratórias

\begin{tabular}{ccccccc}
\hline Modelo & GI & $\boldsymbol{x}^{2}$ & AGFI & CFI & ECVI & RMSEA \\
\hline I & 6 & 10,455 & .97 & .99 & .11 & .038 \\
II & 11 & $30,010^{*}$ & .95 & .99 & .16 & .058 \\
III & 10 & 15,430 & .97 & .99 & .12 & .033 \\
\hline
\end{tabular}

Nota. AGFI = adjusted goodness-of-fit-index; CFI = comparative fit index; ECVI = expected cross-validation index; RMSEA = rootmean-square error of approximation.

${ }^{*} \underline{p}<.005$

Os resultados relativos ao impacto das variáveis cognitivas, motivacionais e psicossociais sobre a adesão às teorias conspiratórias podem ser observados mediante a análise do diagrama apresentado na Figura 4. Nesse caso, nota-se, em consonância com o padrão observado na regressão linear, que o conhecimento exerce uma influência direta sobre o grau de adesão à crença (coeficiente padronizado $=.18$ ). Além desse impacto direto sobre a crença, o conhecimento é um bom preditor das variáveis interesse (coeficiente padronizado $=.56$ ) e filiação (coeficiente padronizado $=$ .35). 


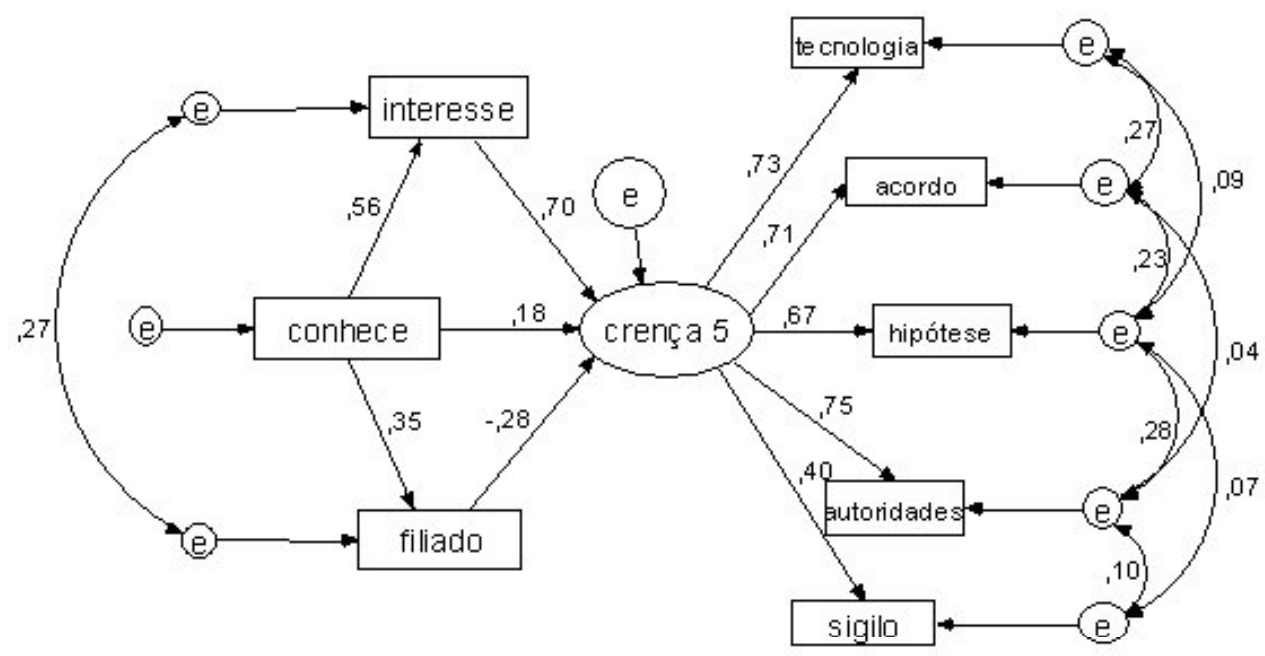

Figura 4.Diagrama da equaçẫo estrutural relativa ao efeito das variáveis psicossociais sobre a adesẫo à crença a respeito dos extraterrestres e as teorias conspiratórias.

De resto, o mesmo padrão identificado na análise da crença anterior permanece, observando-se, uma vez mais, uma poderosa influência do interesse (coeficiente padronizado $=.70$ ) e uma influência um pouco menor da filiação grupal (coeficiente padronizado $=-.28$ ). no grau de adesão às crenças sobre as hipóteses conspiratórias.

\section{Implicações do modelo para a pesquisa sobre as crenças}

As análises apresentadas na seção anterior permitem sustentar que se dispõe de um modelo de boa qualidade acerca da adesão às crenças ufológicas. Os resultados obtidos pela regressão linear indicaram que este modelo possui um poder preditivo relativamente alto (Field, 2004; Tabachnick \& Fidell, 2001) quando comparado com as pesquisas publicadas em periódicos especializados na área de psicologia. A aplicação do modelo alicerçou esta conclusão, ao ser capaz de prever cerca de $80 \%$ das respostas submetidas à análise. Finalmente, um último indicador de que o modelo possui uma qualidade aceitável assenta-se nos índices de ajustamento da equação estrutural que apresentaram valores bastante toleráveis para estudos conduzidos nos domínios das ciências comportamentais.

O fato de o modelo possuir boas propriedades preditivas não significa muita coisa, se ele não representar um avanço no repertório de conhecimento a respeito do assunto. Neste particular, ele pode significar um avanço, pois procura introduzir duas dimensões que não são particularmente exploradas no estudo psicossocial das crenças. Por um lado, ao introduzir dimensões como o grau de conhecimento a respeito do assunto e a filiação grupal, o modelo posiciona-se dentro de uma perspectiva que dificilmente poderia ser reduzida aos pressupostos do individualismo ontológico e metodológico, especialmente no que concerne às explicações a respeito do comportamento social. O modelo, tal como apresentado na sua versão final, exige que sejam levados em consideração não apenas o repertório de conhecimento individual, bem como o nível de interesse de cada participante, mas também impõe que se considere a pertença aos grupos de investigações ufológicas. Isto significa dizer, por exemplo, que aqui não se concebe a possibilidade de postular uma crença grupal ou coletiva que se sobreporia aos indivíduos como uma totalidade transcendente, mas sim que é possível postular nos grupos sociais e nas coletividades a existência de posições a serem ocupadas por determinados indivíduos e que os ocupantes destas posições, justamente por ocuparem estes espaços, se encarregam de imprimir uma forma particular de expressão das crenças, que tendem a ser adotadas pelos demais membros da totalidade.

Um elemento que indica que o modelo aqui exposto se afasta dos princípios do individualismo reside no entendimento de que as crenças submetidas à análise ao longo do trabalho devem ser qualificadas como compartilhadas. Um número grande de exemplares destas crenças encontra-se em circulação no âmbito da comunidade ufológica e muitas destas expressões individuais das crenças são tão semelhantes entre si que os agentes individuais são capazes de reconhecer 
semelhanças entre as suas formulações e as crenças expressas por outros indivíduos (Gaskell \& Fraser, 1990). Se forem consideradas as últimas revisões da literatura publicadas sobre o assunto, o problema do compartilhamento das crenças (ou cognições) na psicologia social permanece mal resolvido (Tindale, Meisenhelder, Dykema-Engblade \& Hogg, 2003), o que se deve a injustificada ausência de considerações sobre os níveis de explicação na psicologia social (Doise, 1986).

A questão do nível de explicação é a segunda dimensão contemplada pelo modelo aqui exposto, pois este leva em conta não apenas variáveis subordinadas ao plano individual (grau de conhecimento e interesse) e grupal (filiação), como também postula hipóteses a respeito de qual o tipo de relação estabelecida entre estas variáveis.

Como todo modelo, o aqui apresentado não possui a pretensão de ser exaustivo ou completo. Alguns fatores foram deliberadamente excluídos da versão final, como, por exemplo, as variáveis demográficas idade, gênero e nível de escolaridade. Afora isso, outras variáveis psicossociais, tais como a identidade social ou o auto-conceito, não foram consideradas no presente modelo. A exclusão das variáveis demográficas se deve a uma série de razões. No caso da idade, embora tenham sido encontrados indicadores que grau de adesão à crença aumenta progressivamente com a idade, a contribuição desta variável para o modelo é bastante modesta. No que concerne ao gênero, não foram encontradas diferenças significativas no padrão de adesão às crenças ufológicas entre homens e mulheres, embora, o gênero masculino seja bem mais representativo na amostra, assim como nos grupos ufológicos. Quanto ao grau de escolaridade, embora sejam encontradas razões acreditar que o grau de elaboração ou sofisticação das crenças depende, em certa medida, da educação formal, os resultados apontam que o impacto desta variável é pouco significativo no nível de adesão às crenças ufológicas. Um outro problema com o modelo aqui apresentado relaciona-se com a ausência de qualquer consideração a respeito do impacto das relações intergrupais e de como estas desempenham um papel decisivo na constituição da identidade social. Uma vez que os grupos humanos não surgem e nem se desenvolvem em um vazio social, as relações entre os diferentes grupos ufológicos entre si, destes com os grupos de céticos e com outros grupos importantes (religiosos, por exemplo) deveriam ser contempladas no presente modelo.

As variáveis consideradas no presente modelo proporcionam a possibilidade de refletir sobre uma série de elementos importantes a respeito da manifestação das crenças compartilhadas sobre os extraterrestres e os objetos voadores não-identificados. Conforme se observa nos dois modelos aqui expostos, a variável que exerce o maior poder preditivo é o interesse pelo assunto. Observou-se uma relação diretamente proporcional entre o grau de interesse e a intensidade de adesão à crença. Um elemento importante para o esclarecimento desta relação pode ser identificado desde que consideremos as contribuições de alguns estudos psicossociais sobre o processo de crer. Neste caso, não é possível deixar de considerar a distinção estabelecida por Gilbert (1991) entre as teorias cartesiana e espinoziana sobre o crer. A primeira destas teorias sugere que as crenças são aceitas apenas nas circunstâncias em que aquele que crê julga e avalia cuidadosamente todas as peças de informação necessárias e apenas após este julgamento decide se a conjectura possui elementos suficientes para fundamentar a decisão de adesão à crença. A teoria espinoziana, ao contrário, sugere que inicialmente se adere à crença e apenas posteriormente, desde que sejam encontradas razões suficientes para colocar em dúvida os fundamentos da crença, passa-se a conduzir um julgamento acurado a respeito da validade das bases informacionais que permitem aceitar aquilo em que se acredita. A partir desta distinção, pode-se supor que as pessoas que possuem um grande interesse pelo assunto tendem a ser espinozianas no modo de acreditar, no sentido que dificilmente colocam em dúvida os fundamentos daquilo em que acreditam, enquanto aquelas com um interesse mais limitado tendem a aderir ao princípio cartesiano.

A utilização de atalhos mentais pode explicar esta diferenciação no nível de adesão às crenças ufológicas. Uma vez que o sistema de processamento de informações humano pode ser caracterizado limitado no que concerne ao poder e à velocidade do processamento da informação, não é difícil compreender a utilização de estratégias heurísticas para simplificar os problemas que emergem durante o processo de julgamento e tomada de decisões, sendo particularmente importante, no presente caso, a heurística da acessibilidade (Hamilton e Sherman, 1996; Kahneman, 2003). Neste caso, o julgamento é realizado com base na facilidade ou na extensão com que determinado conteúdo pode ser acessado na memória. Assim sendo, é possível supor que o grau de acessibilidade às informações de natureza ufológica deve ser bem maior entre as pessoas que se interessam de forma intensa sobre o assunto, que certamente devem ler com mais freqüência livros e revistas de ufologia, acessar mais 
amiúde websites dedicados aos assuntos ufológicos e participar de listas de discussão sobre o assunto, podendo-se supor, portanto, que a facilidade de acesso aos conteúdos ufológicos pode favorecer a aceitação de explicações que não seriam facilmente corroboradas por indivíduos que não acessam freqüentemente este tipo de informação na memória.

Um dos aspectos mais intrigantes dos dados aqui apresentados relaciona-se com o efeito negativo da filiação grupal na intensidade de adesão às duas crenças consideradas no presente estudo. $\mathrm{O}$ que explica esta redução no nível de adesão às crenças entre aqueles que se encontram filiados aos grupos ufológicos quando comparados aos participantes que pretendem vir a se filiar aos grupos ufológicos? A resposta a esta questão demanda considerações a respeito de processos que se manifestam no plano intra e intergrupal.

Uma forma básica de imposição de padrões de compartilhamento de crenças aos membros de um grupo social depende do impacto da comparação social (Helgeson \& Mickelson, 1995; Wood, 1996; um instrumento de mensuração da comparação social pode ser encontrado em Gibbons \& Buunk, 1999). Conforme expressa por Leon Festinger, a teoria da comparação social sustenta-se em dois princípios. Inicialmente, ela supõe que necessitamos constantemente avaliar nossas crenças, com a finalidade de julgar se estamos a agir adequadamente. Em segundo lugar, ela supõe que dada a impossibilidade de realizar esta avaliação objetivamente, nos associamos aos outros para obtermos as informações que desejamos. Por extensão, pode-se afirmar que nas circunstâncias em que a realidade física não oferece pistas suficientes para a formalização de uma opinião ou para a manifestação de um comportamento, a realidade social passa a se encarregar deste papel. Pode-se presumir, conseqüentemente, que a comparação com os membros do grupo faz com que os participantes dos grupos de investigações ufológicas tendam a diminuir as incertezas, isto é, ao conhecer melhor os princípios e os procedimentos da pesquisa ufológica ou ao manterem um maior contato com a casuística tendam a reduzir tanto a intensidade quanto a amplitude das crenças, passando a considerar como insustentáveis pontos de vista e opiniões amplamente aceitas por pessoas que não participam dos grupos ufológicos.

Um aspecto importante relaciona-se com o processo de comunicação que se manifesta no âmbito dos grupos (Geiger \& Bradac, 1999; Roberts \& Maccoby, 1985). Um princípio básico da comunicação intragru- pal sustenta-se na suposição de que as trocas comunicacionais entre os membros de um grupo tende a ser percebida como mais válida que a comunicação que permanece insulada ou exclusiva de um número reduzido de membros, uma vez que o compartilhamento e a intensificação de trocas comunicacionais sobre um determinado tópico tende a impor uma série de mudanças graduais no significado do objeto da comunicação até que se alcance uma certa convergência e acordo a respeito dos significados atribuídos aos elementos em discussão. Neste particular, o acordo pode se estender inclusive aos elementos que são vistos como boatos, inverdades ou mesmo fraudes, o que faz com que os membros dos grupos ufológicos tenham condições de adotar uma postura mais crítica e parcimoniosa do que aqueles que pretendem vir a participar de grupos ufológicos e que, nesse sentido, tendem a se encontrar mais expostos a informações com um menor teor crítico e de natureza eminentemente confirmatória.

Finalmente, um outro aspecto a ser consideração envolve as normas grupais, uma vez que estas descrevem e prescrevem as atitudes e condutas apropriadas a serem seguidas pelos membros do grupo em um determinado contexto (Forsyth, 1999). Uma vez que estas podem ser definidas como padrões ou expectativas de comportamentos partilhados pelos membros do grupo, pode-se esperar uma maior pressão no sentido de controlar a expressão de opiniões passíveis de serem interpretados como elementos que possam expressar posições ingênuas ou uma postura não ortodoxa com as crenças grupais.

O papel do grau de conhecimento como variável preditiva dos modelos aqui apresentados deve ser considerado cuidadosamente, pois, conforme se observa nos diagramas apresentados nas Figuras 3 e 4, o impacto é muito mais acentuado sobre a filiação grupal e o interesse pelo assunto do que sobre as crenças em si. Uma outra modalidade de heurística, a do ajustamento, pode vir a ocupar um papel considerável na compreensão do impacto do nível de conhecimento sobre as crenças. Por heurística do ajustamento se entende a dificuldade comum aos agentes cognitivos em modificar crenças mais antigas, ainda que sejam oferecidas informações que poderiam facilmente a rejeitar aquilo em que se acredita. Estudos desenvolvidos por Latané e colaboradores apontam que os indivíduos tendem a modificar os seus próprios pontos de vista apenas nas circunstâncias em que o poder persuasivo sugerido pelos novos argumentos ultrapasse de forma acentuada as condições que favorecem a manutenção de crenças mais antigas (Latané, 1981; 
Latané \& L’Herrou, 1996). Uma vez que as pessoas tendem a se agrupar no espaço em função da similaridade das crenças, o que faz que por mais que o ponto de partida seja uma distribuição aleatória de crenças, estas tendem a se agrupar, posteriormente, em conjuntos diferenciados. A consolidação deste espaço de distribuição das crenças desenvolver-se-á de tal forma que as posições majoritárias tenderão a se fortalecer cada vez mais, impondo uma homogeneidade na expressão das crenças, enquanto as posições minoritárias tenderão a conhecer um refluxo, ainda que isto não venha a significar o desaparecimento completo das posições idiossincráticas e particulares.

\section{Uma agenda de investigações sobre as crenças, em particular sobre as crenças ufológicas}

O enorme impacto exercido pelo livro Crenças, Atitudes e Valores, de Milton Rokeach, é um forte indicador da importância do estudo das crenças na psicologia social. Apesar desta constatação, é impossível deixar de considerar que este impacto é bem menor do que seria merecido pela importância do assunto (Rokeach, 1981). Embora algumas teorias, como, por exemplo, a teoria atitudinal de Fishbein e Azjen e outras de menor repercussão, dêem uma atenção particular ao tema, esta atenção não parece ser suficiente para colocá-lo no lugar de merecido destaque. Somos, nesse particular, aquilo que acreditamos ser e aquilo em que acreditamos ser nos faz ser o que somos. Acreditamos que somos quem somos, porque não temos dúvidas a respeito da nossa identidade pessoal, e não temos intenção de duvidar que as pessoas são exatamente aquilo que elas crêem e dizer ser. Da mesma forma, temos crenças a respeito dos nossos gostos, das nossas idiossincrasias, dos eventos que ocorreram em nosso passado e dos nossos planos para o futuro. Acreditamos que o mundo é tal como ele se nos apresenta e temos crenças sobre o que e como é possível modificá-lo para que este se torne aquilo em que acreditamos que ele deveria ser. $\mathrm{O}$ estudo das crenças ufológicas pode contribuir para o desenvolvimento do estudo das crenças na medida em que introduz uma dimensão que pode vir a modificar por inteiro as crenças que disponíveis sobre a humanidade, sobre cada um de nós e sobre o universo no qual estamos inseridos.

O estudo aqui desenvolvido deixou uma série de lacunas que necessitam de um melhor desenvolvimento para que possamos aceder a uma compreensão mais ampla do tema. Antes de qualquer coisa, torna-se necessário desenvolver uma tipologia dos que crêem.
Os resultados obtidos na pesquisa empírica aqui referida apontam perfis claramente diferenciados entre as crenças dos participantes. Os céticos, por exemplo, não crêem na existência de objetos voadores não identificados, nem muito menos que eles sejam oriundos de civilizações extraterrestres e nem mesmo aceitam a tese de que os alienígenas se encontram entre nós. Em contrapartida, muitos participantes do estudo acreditam não só que os extraterrestres se encontram entre nós, como também que o planeta terra é habitado por várias raças alienígenas e que o nosso mundo é o palco de inúmeras batalhas intergalácticas. Entre estas duas posições extremadas, podemos identificar matizes variados de crenças e de crentes. O desenvolvimento de uma tipologia dos que crêem poderá contribuir para o esclarecimento das diferenças de opiniões e de padrões de ação, ajudando a entender melhor porque alguns dos que acreditam se filiam a grupos ufológicos, outros se interessam apenas pela leitura de livros e revistas de ficção científica e ufologia, enquanto outros apenas acreditam, sem que isso venha a produzir alguma ação, a não ser a mera contemplação desinteressada. Da mesma forma, entre os que não crêem, alguns não vêem como sustentar e defender as hipóteses ufológicas e apenas julgam com uma certa condescendência os que crêem em discos voadores e invasões extraterrestres, enquanto outros se tornam militantes anti-ufológicos não perdendo oportunidade para desqualificar os argumentos daqueles a quem consideram crédulos.

Afora esta necessidade de estabelecer uma tipologia dos que crêem, no que concerne ao desenvolvimento futuro das investigações sobre as crenças ufológicas, torna-se imperativo identificar o efeito exercido pelas crenças religiosas. Embora a equação de regressão preditora da crença sobre os extraterrestres e a humanidade tenha incluído as variáveis religião espírita e católica e tenha apontado a contribuição positiva da filiação a estas religiões no endossamento da crença, talvez seja necessário modificar esta abordagem e incluir não a religião em si, declarada por meio de auto-relato, mas sim elaborar uma escala a respeito de crenças religiosas de forma a identificar como grau de religiosidade - especialmente um tipo de religiosidade difusa que flerta com o espiritualismo, o misticismo, as religiões orientais e as práticas mágicas - influencia a adesão às crenças de natureza ufológicas.

Enfim, um último ponto a se considerar no desenvolvimento de uma agenda de estudos sobre as crenças ufológicas resvala diretamente no plano das rela- 
ções intergrupais. Em que pese a adesão a alguns princípios básicos, os grupos ufológicos mantêm entre si diferenças de magnitude razoáveis. Muitos ufólogos postulam uma distinção entre a ufologia científica e a ufologia mística. Esta distinção não é um mero formalismo, uma vez que ela recobre não apenas crenças diferenciadas a respeito da natureza dos alienígenas (extraterrestres ou seres dimensionais) das origens dos objetos voadores não identificados (extraterrestres ou ultraterrestres), da finalidade da presença dos visitantes (contatos ou abduções), bem como impõe uma diferenciação bastante rígida entre os afazeres dos ufólogos, especialmente no que concerne aos métodos de investigação, aos procedimentos de obtenção de evidências empíricas, às relações com a comunidade científica e com os meios de comunicação de massa.

\section{REFERÊNCIAS}

Bem, D. (1973). Conviç̧ões, atitudes e assuntos humanos (C. M. Bori, Trad.). São Paulo: EDUSP/EPU.

Byrne, B. (2001). Structural equation modeling with AMOS: Basic concepts, applications, and programming. Mahwaw, NJ: Lawrence Erlbaum.

Doise, W. (1986). Levels of explanation in social psychology. Cambridge University Press.

Field, A. (2004). Discovering statistics using SPSS for Windows. London: Sage.

Forsyth, D. (1999). Norms. Em A. Manstead \& M. Hewstone (Orgs.), The Blackwell encyclopedia of social psychology (p. 412-417). Oxford: Blackwell.

Gaskell, G., \& Fraser, C. (1990). The social psychological study of widespread beliefs. Em C. Fraser \& G. Gaskell (Orgs.), The social psychological study of widespread beliefs (p. 3-23). Oxford: Clarendon Press.

Geiger, S., \& Bradac, J. (1999). Communications. Em A. Manstead \& M. Hewstone (Orgs.), The Blackwell encyclopedia of social psychology (p. 109-114). Oxford: Blackwell.

Gibbons, F., \& Buunk, B. (1999). Individual differences in social comparison: Development of a scale of social comparison orientation. Journal of Personality and Social Psychology, 76, 129-142.

Gilbert, D. (1991). How mental systems believe. American Psychologist, 46(2), 107-119.
Hamilton, D., \& Sherman, S. (1996). Perceiving persons and groups. Psychological Review, 103(2), 336-355.

Helgeson, V., \& Mickelson, K. (1995). Motives for social comparison. Personality and Social Psychology Bulletin, 21, 12001209.

Kahneman, D. (2003). A perspective on judgement and choice: Mapping bounded rationality. American Psychologist, 58(9), 697-720.

Krüger, H. (1995). Psicologia das crenças: Perspectivas teóricas. Tese não publicada de concurso para professor titular do Departamento de Psicologia Social e Institucional da Universidade do Estado do Rio de Janeiro.

Latané, B. (1981). The psychology of social impact. American Psychologist, 36(4), 343-355.

Latané, R., \& L'Herrou, T. (1996). Social clustering in the conformity game: Dynamic social impact in electronic groups. Journal of Personality and Social Psychology, 70, 1218-1230.

Oakhill, J., \& Garnham, A. (1993). On theories of belief bias in syllogistic reasoning. Cognition, 46, 87-92.

Pereira, M. (2002). Psicología social dos estereótipos. São Paulo: EPU.

Pereira, M., Silva, J., \& Silva, P. (2006). Investigações psicológicas no ciberespaço: O impacto do interesse, filiação grupal e conhecimento na adesão às crenças ufológicas. Interação em Psicologia, 10(2), 375-384.

Roberts, D., \& Maccoby, N. (1985). Effects of mass communications. Em G. Lindzey \& E. Aronson (Orgs.), Handbook of social psychology: Vol. 2 (p. 539-598). New York: Random House.

Rokeach, M. (1960). The open and closed mind. New York: Basic Books.

Rokeach, M. (1981). Crenças, atitudes e valores (A. M. M. Barbosa, Trad.). Rio de Janeiro: Interciência.

Tabachninck, B., \& Fidell, L. (2001). Using multivariate statistics. Needham Heights: Allyn \& Bacon.

Tindale, R., Meisenhelder, H., Dykema-Engblade, A., \& Hogg, M. (2003). Shared cognition in small groups. Em M. Hoog \& S. Tindale (Orgs), Blackwell handbook of social psychology: Group processes (p. 1-30). Oxford: Blackwell.

Wood, J. (1996). What is social comparison and how should we study it? Personality and Social Psychology Bulletin, 22, 520537.

Recebido: 27/05/2006

Revisado: 04/05/2007

Aceito: 09/06/2007

\section{Sobre o autor:}

Marcos Emanoel Pereira: Professor Adjunto do Departamento de Psicologia/Programa de Pós-Graduação em Psicologia da Universidade Federal da Bahia.

Endereço para correspondência: Marcos Emanoel Pereira - Rua Rodrigo Argollo, 293/502, Rio Vermelho, Salvador, BA - 41940-220

- Endereço eletrônico: emanoel@terra.com.br 
